Supporting Information

\title{
Twin-Directed Deposition of Pt on Pd Icosahedral Nanocrystals for Catalysts with Enhanced Activity and Durability toward Oxygen Reduction
}

Mingkai Liu, Zhiheng Lyu, Yu Zhang, Ruhui Chen, Minghao Xie, Younan Xia* 
Materials. Sodium tetrachloropalladate $\left(\mathrm{Na}_{2} \mathrm{PdCl}_{4}, 98 \%\right)$, potassium tetrachloroplatinate $\left(\mathrm{K}_{2} \mathrm{PtCl}_{4}, 98 \%\right.$ ), poly(vinyl pyrrolidone) (PVP, MW $\left.\approx 55,000\right)$, diethylene glycol (DEG), Lascorbic acid (AA), and potassium bromide $(\mathrm{KBr})$ were obtained from Sigma-Aldrich. Deionized (DI) water with a resistivity of $18.2 \mathrm{M} \Omega \cdot \mathrm{cm}$ at room temperature was used in all the experiments.

Synthesis of $P d$ icosahedra. The Pd icosahedra with an average size of $9.5 \mathrm{~nm}$ were synthesized according to our previously reported protocol. ${ }^{1}$ Typically, $160 \mathrm{mg}$ of PVP was dissolved in $4 \mathrm{~mL}$ of DEG in a 20 - $\mathrm{mL}$ vial by heating at $130{ }^{\circ} \mathrm{C}$ for $10 \mathrm{~min}$ under magnetic stirring. Subsequently, $31 \mathrm{mg}$ of $\mathrm{Na}_{2} \mathrm{PdCl}_{4}$ was dissolved in $2 \mathrm{~mL}$ of DEG and the solution was injected into the PVP solution in one shot. This reaction was maintained at $130{ }^{\circ} \mathrm{C}$ for $3 \mathrm{~h}$ under magnetic stirring. The solid product was collected by centrifugation, washed once with acetone and twice with water, and dispersed in $6 \mathrm{~mL}$ of water for further use.

Synthesis of Pd-Pt great icosahedra. In a standard protocol, $1 \mathrm{~mL}$ of the aqueous suspension of Pd icosahedra, $70 \mathrm{mg}$ of PVP, $50 \mathrm{mg}$ of AA, and $4 \mathrm{~mL}$ of water were mixed in a $20-\mathrm{mL}$ vial and heated at $30{ }^{\circ} \mathrm{C}$ for 20 min under magnetic stirring. At the same time, $3.5 \mathrm{mg}$ of $\mathrm{KBr}$ and $1.5 \mathrm{mg}$ of $\mathrm{K}_{2} \mathrm{PtCl}_{4}$ were dissolved in $2 \mathrm{~mL}$ of water and the solution was added into the vial in one shot. The reaction was maintained at $30{ }^{\circ} \mathrm{C}$ for another $24 \mathrm{~h}$. The solid product was collected by centrifugation, washed once with acetone and twice with water, and dispersed in $2 \mathrm{~mL}$ of water.

Characterization. Transmission electron microscopy (TEM) images were taken using a Hitachi HT7700 microscope operated at $120 \mathrm{kV}$. High-resolution TEM images and energy-dispersive X-ray (EDX) spectroscopy data were acquired on an aberration-corrected Hitachi HD-2700 scanning TEM (STEM) equipped with a Brüker Quantax 400/S-STEM EDX detector at $200 \mathrm{kV}$. Before imaging, the sample was cleaned in a Hitachi Zone cleaner for $30 \mathrm{~min}$ at a pressure setting of 30. X-ray photoelectron spectroscopy (XPS) measurements were conducted using a Thermo Scientific K-Alpha spectrometer with an Al Ka microfused monochromic source. 
Preparation of the working electrode. Separately, $5 \mathrm{mg}$ of the Pd-Pt great icosahedra were dispersed in $5 \mathrm{~mL}$ of water and $15 \mathrm{mg}$ of carbon support (Vulcan $\mathrm{XC}-72$ ) was dispersed in 10 $\mathrm{mL}$ of water. These two suspensions were then mixed together under sonication at room temperature, followed by sonicating for another $3 \mathrm{~h}$. The carbon-supported catalyst was collected by centrifugation at 15,000 rpm, and then dispersed in $12 \mathrm{~mL}$ of acetic acid, treated at $60{ }^{\circ} \mathrm{C}$ for $3 \mathrm{~h}$ under magnetic stirring to remove excess PVP. The solid was collected by centrifugation and washed with ethanol eight times to further clean the surface. The final product was dried at $70{ }^{\circ} \mathrm{C}$ for $2 \mathrm{~h}$. In the following step, $16.4 \mathrm{mg}$ of the catalyst was dispersed in a mixture of $3.98 \mathrm{~mL}$ of isopropanol and $20 \mu \mathrm{L}$ of $5 \%$ Nafion under ultrasonication for $1 \mathrm{~h}$. The final concentration of $\mathrm{Pt}$ in the as-prepared catalyst was determined to be $0.256 \mathrm{mg} \cdot \mathrm{mL}^{-1}$ by inductively coupled plasma mass spectrometry (ICP-MS, NexION 300Q, Perkin-Elmer). $8 \mu \mathrm{L}$ of the suspension was deposited on a pre-cleaned glassy carbon rotating disk electrode (RDE, $0.196 \mathrm{~cm}^{2}$ in geometric area, Pine Research Instrumentation) and dried at room temperature. The working electrode was further dried at $60{ }^{\circ} \mathrm{C}$ for $1 \mathrm{~h}$ in an oven. Commercial Pt/C (20 wt\%, Pt nanoparticles on Vulcan XC-72 carbon support; E-TEK) was prepared with the same protocol and used for comparison.

Electrochemical measurements. All the measurements were conducted in a three-electrode system connected to a CHI 600E electrochemical workstation ( $\mathrm{CH}$ Instruments). A Hydroflex reference electrode (Gaskatel) was used as the reference electrode, a Pt mesh as the counter electrode, and $0.1 \mathrm{M}$ aqueous $\mathrm{HClO}_{4}$ solution as the electrolyte. The cyclic voltammetry (CV) curves were recorded in a $\mathrm{N}_{2}$-saturated $0.1 \mathrm{M} \mathrm{HClO}_{4}$ aqueous solution at a scanning rate of $50 \mathrm{mV} \cdot \mathrm{s}^{-1}$ in the potential range of $0.05-1.1 \mathrm{~V}_{\mathrm{RHE}}$ (RHE: reversible hydrogen electrode). Electrochemical active surface areas (ECSAs) were calculated from the average charges associated with the adsorption of hydrogen from 0.05 to $0.4 \mathrm{~V}$ after double-layer correction with a reference value of $210 \mu \mathrm{C} \cdot \mathrm{cm}^{-2}{ }^{2}$ The ORR activity of each sample was investigated by conducting the linear sweep voltammetry (LSV) tests in an $\mathrm{O}_{2}$-saturated $0.1 \mathrm{M} \mathrm{HClO}_{4}$ solution at room temperature at a scanning rate of $10 \mathrm{mV} \cdot \mathrm{s}^{-1}$ (rotating speed: 1,600 rpm). The data were corrected by $85 \%$ IR drop compensation. The accelerated durability tests (ADTs) 
were carried out in the range of 0.6-1.1 $\mathrm{V}_{\mathrm{RHE}}$ for 5,000 and 10,000 cycles at a scan rate of $100 \mathrm{mV} \cdot \mathrm{s}^{-1}$ in $\mathrm{O}_{2}$-saturated $0.1 \mathrm{M} \mathrm{HClO}_{4}$ solution. The kinetic current was calculated based on the derived Koutecky-Levich equation:

$$
j_{k}=\frac{j_{l} \times j}{j_{l}-j}
$$

where $j_{k}$ is the kinetic current, $j_{l}$ is the diffusion-limiting current, and $j$ is the current experimentally measured at $0.9 \mathrm{~V}_{\mathrm{RHE}}$. Mass and specific activities of samples were obtained by normalizing the kinetic current to the amount of loaded Pt and ECSA value, respectively. 


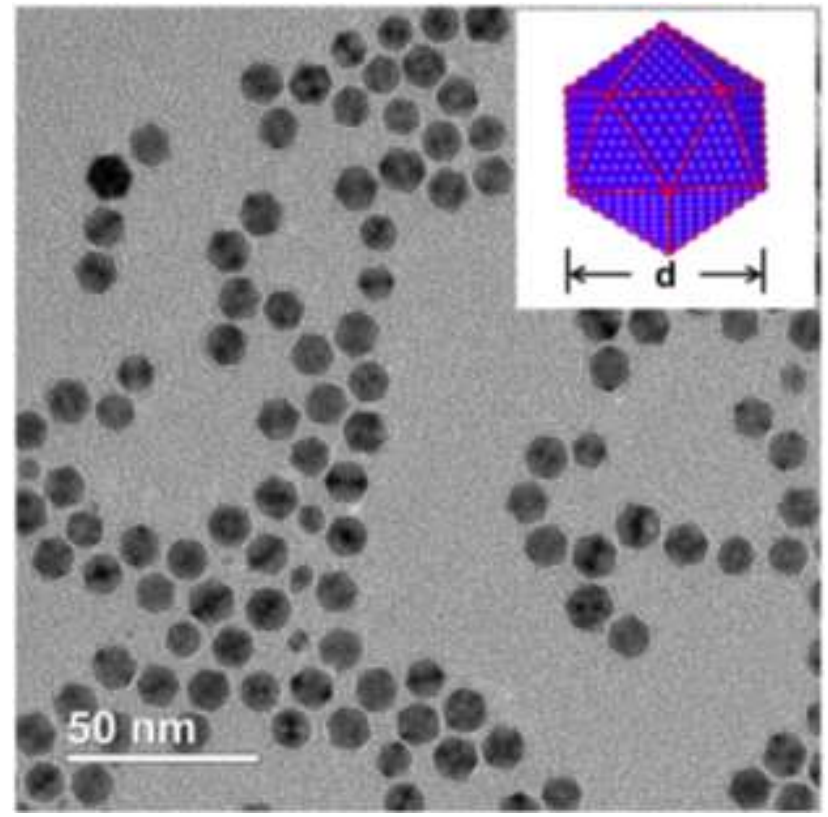

Figure S1. A typical TEM image of the Pd icosahedral seeds, with the inset illustrating the definition of size. 

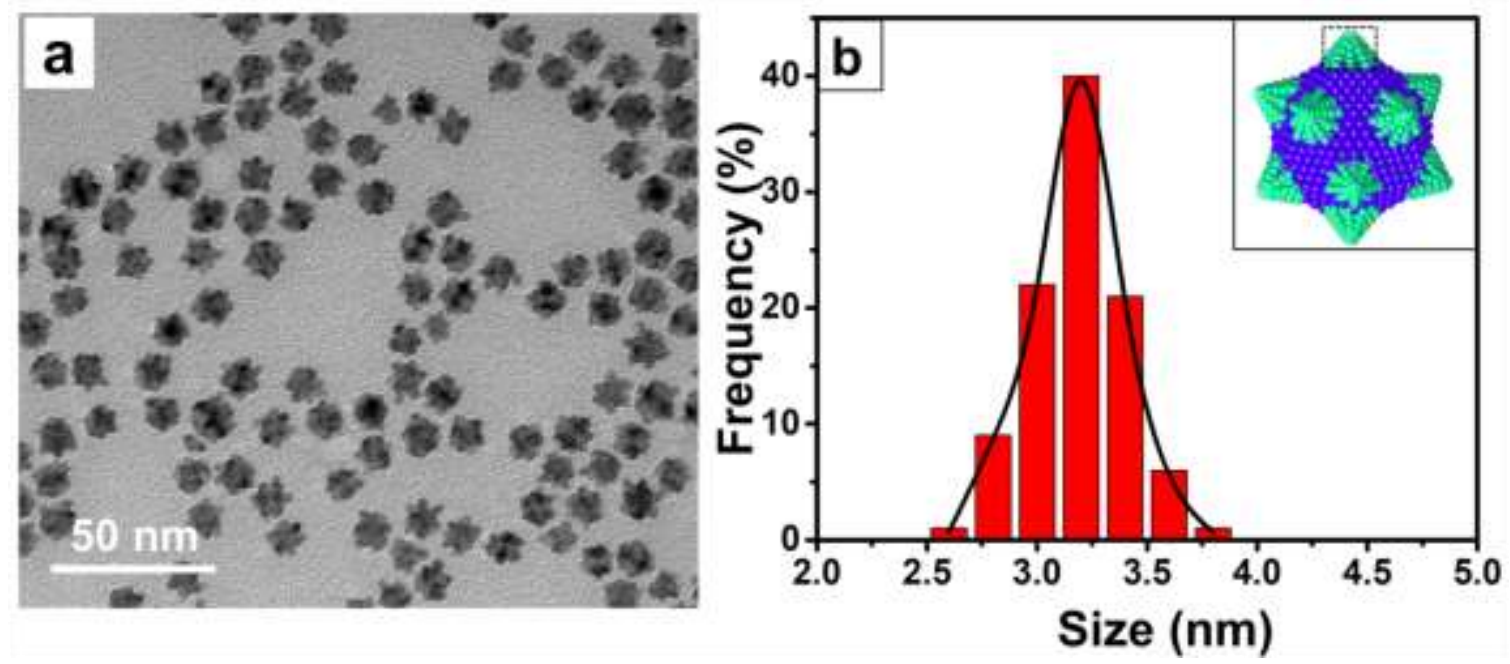

Figure S2. (a) TEM image of the as-synthesized Pd-Pt great icosahedra and (b) the size distribution of the multiply-twinned Pt dots (see the inset for a model, with the size of the dot being defined by its height). 

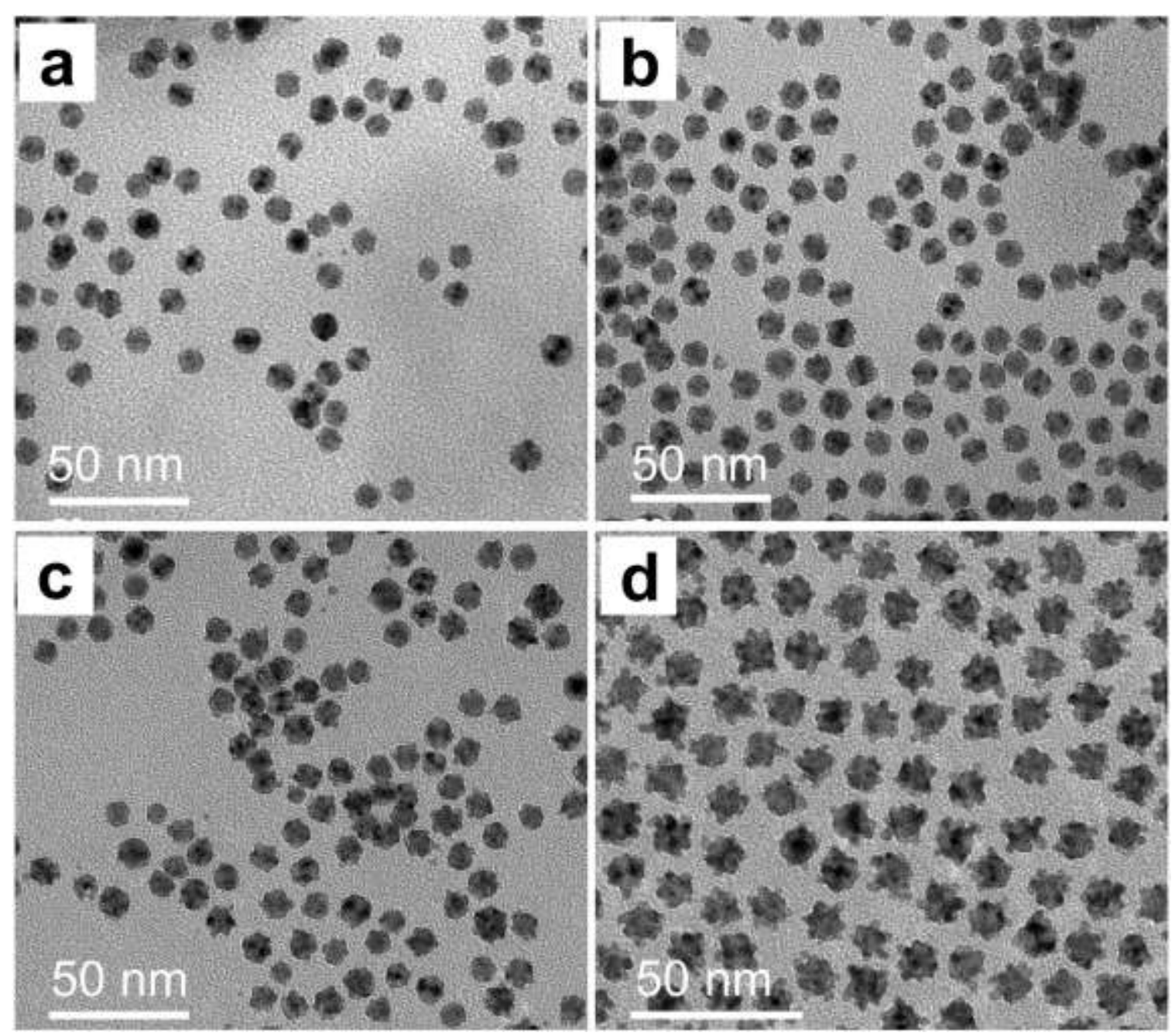

Figure S3. TEM images of the Pd-Pt bimetallic nanocrystals prepared using the standard protocol except for the variation in the amount of $\mathrm{K}_{2} \mathrm{PtCl}_{4}$ : (a) 0.2 , (b) 0.5 , (c) 1.0 , and (d) 2.0 $\mathrm{mg}$, respectively. 

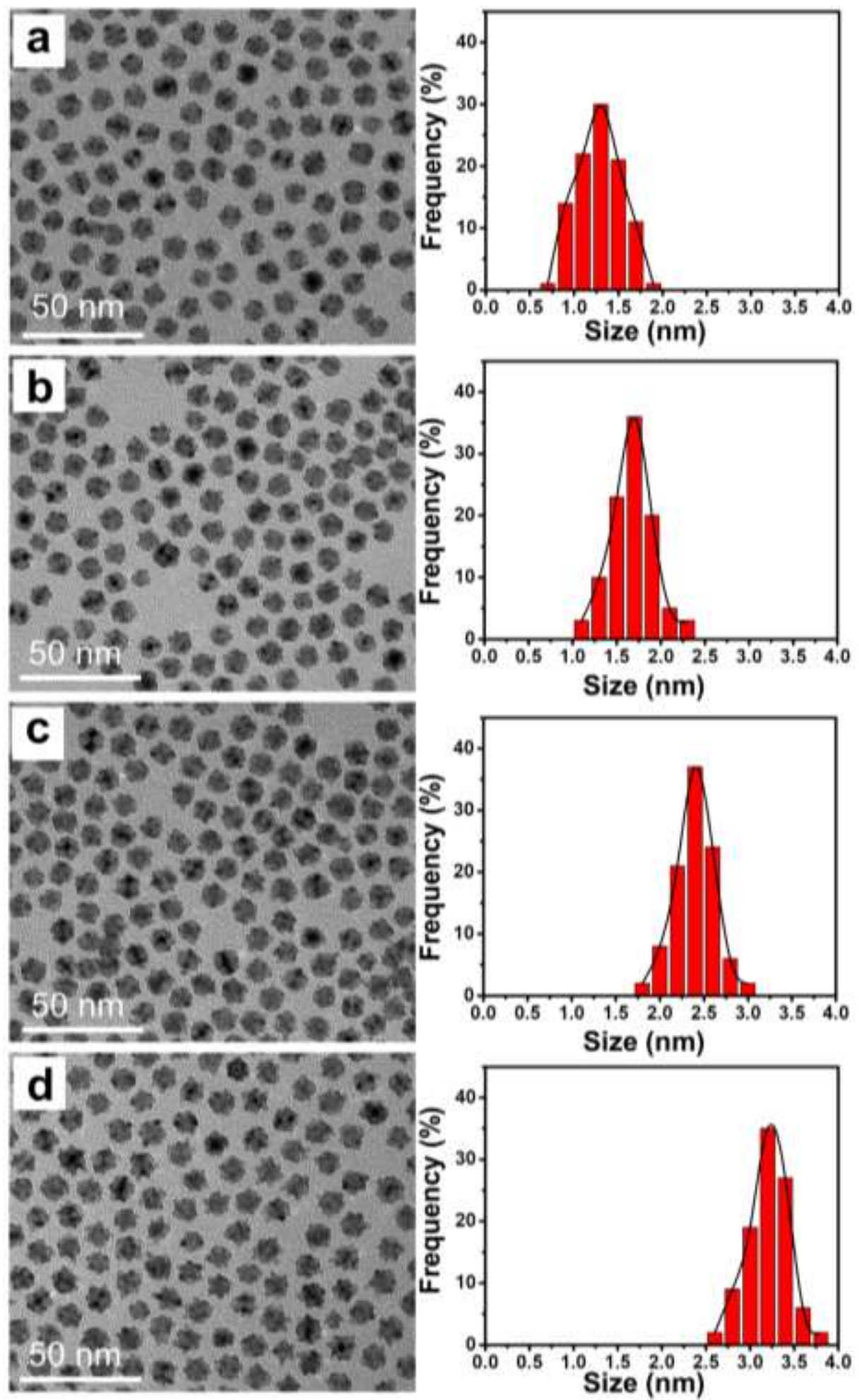

Figure S4. TEM images of the Pd-Pt bimetallic nanocrystals prepared using the standard protocol except for the variation in reaction time: (a) 6, (b) 12, (c) 18, and (d) $24 \mathrm{~h}$, respectively. The plots in the right column represent the corresponding size distributions of the Pt dots deposited on the Pd icosahedral seeds. 


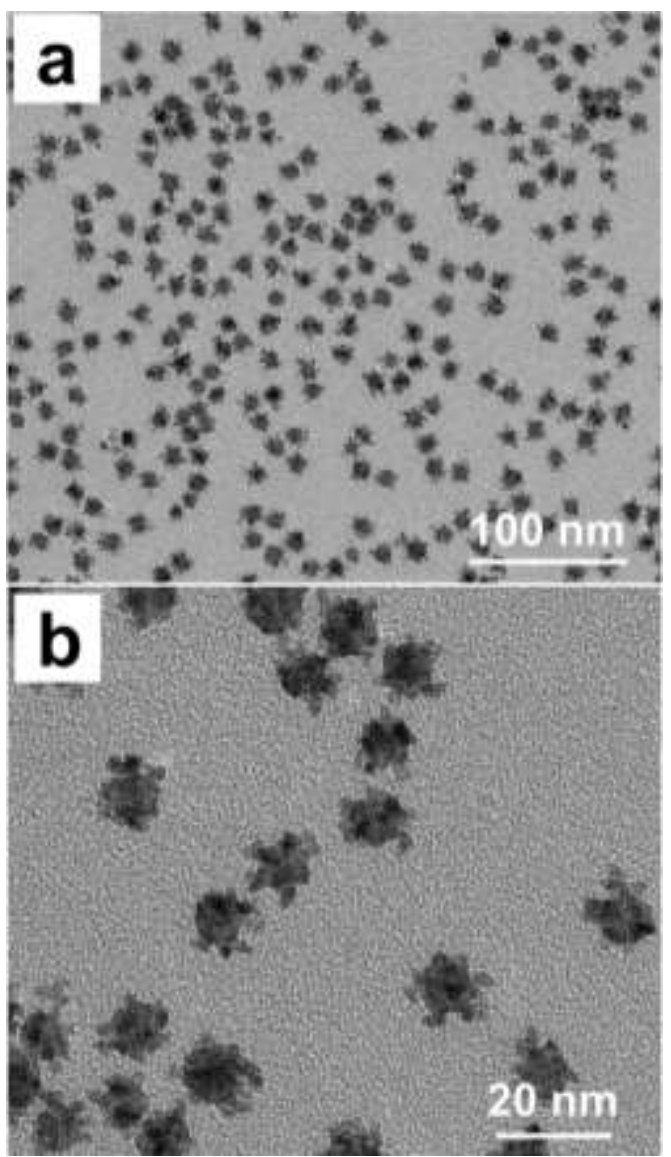

Figure S5. TEM images, at two different magnifications, of the Pd-Pt bimetallic nanocrystals prepared using the standard protocol except for the absence of $\mathrm{Br}^{-}$. 


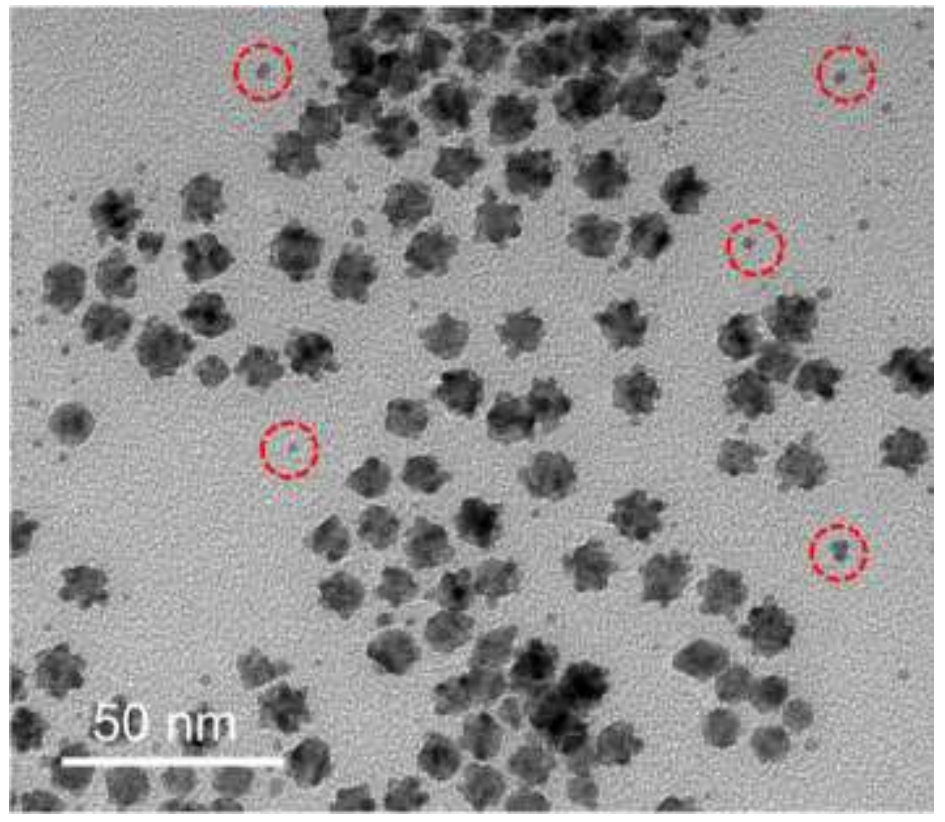

Figure S6. TEM image of the Pd-Pt nanocrystals prepared using the standard protocol except for raising the reaction temperature to $90{ }^{\circ} \mathrm{C}$. The circles indicate the Pt nanoparticles formed through homogeneous nucleation. 


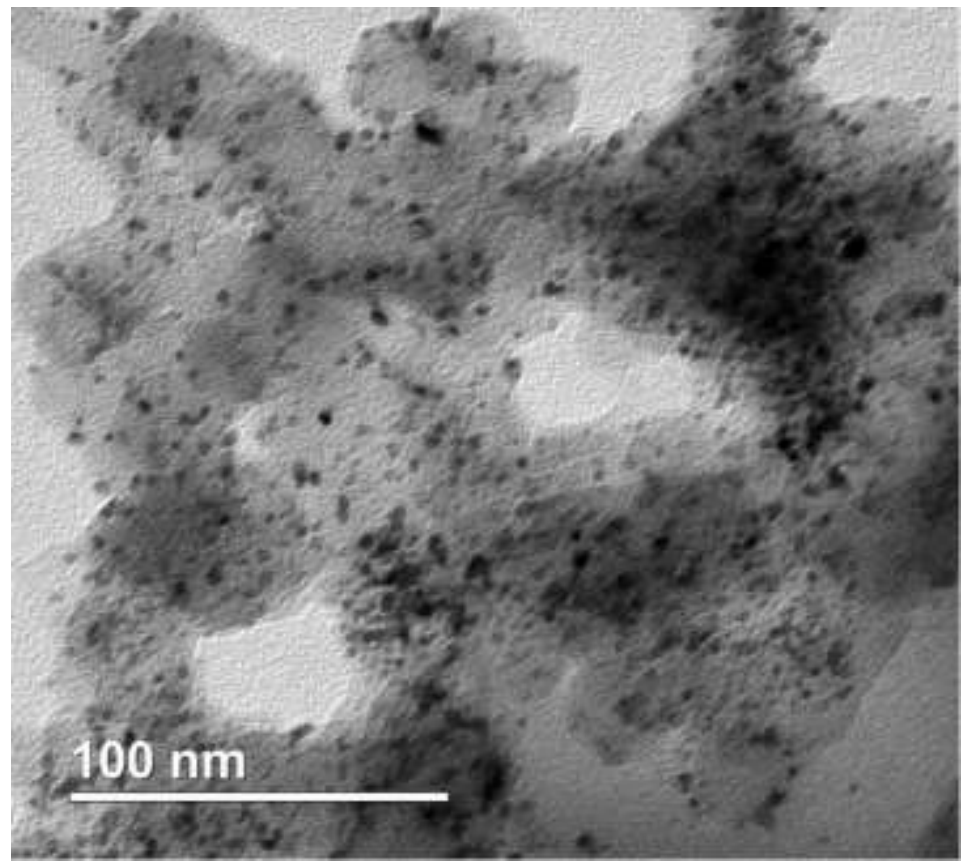

Figure S7. TEM image of the commercial Pt/C catalyst. 


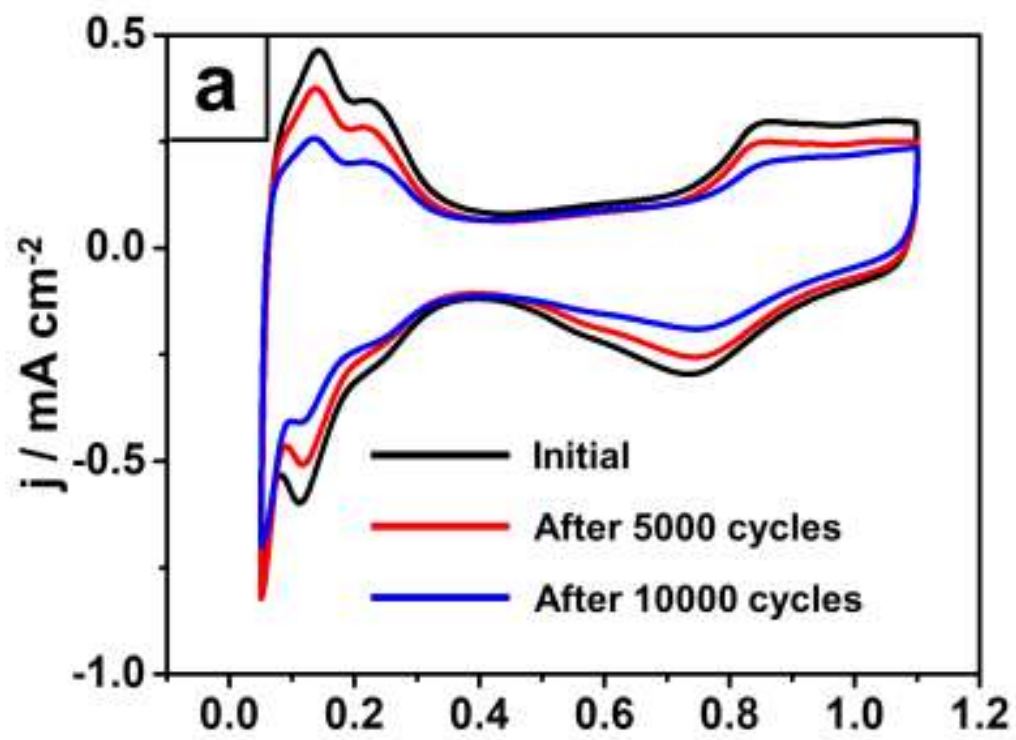

E / V vs. RHE

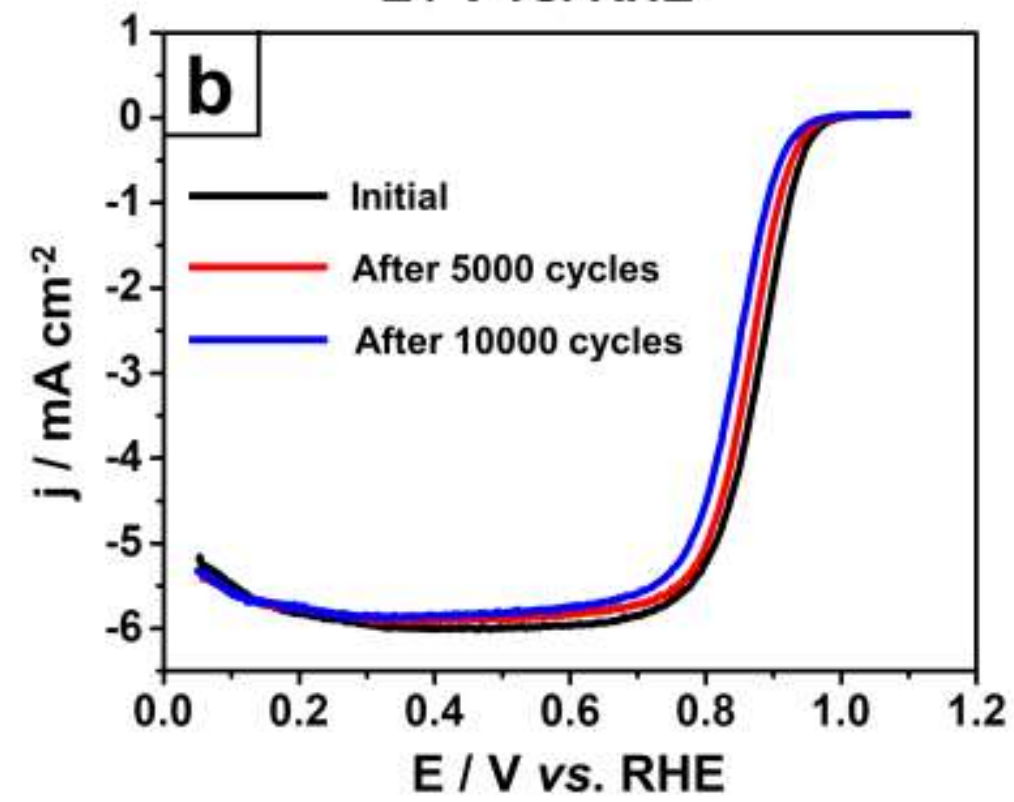

Figure S8. (a) CV and (b) oxygen reduction polarization curves recorded from the commercial $\mathrm{Pt} / \mathrm{C}$ catalyst before and after different cycles of ADT. The currents were normalized to the geometric area of RDE. 


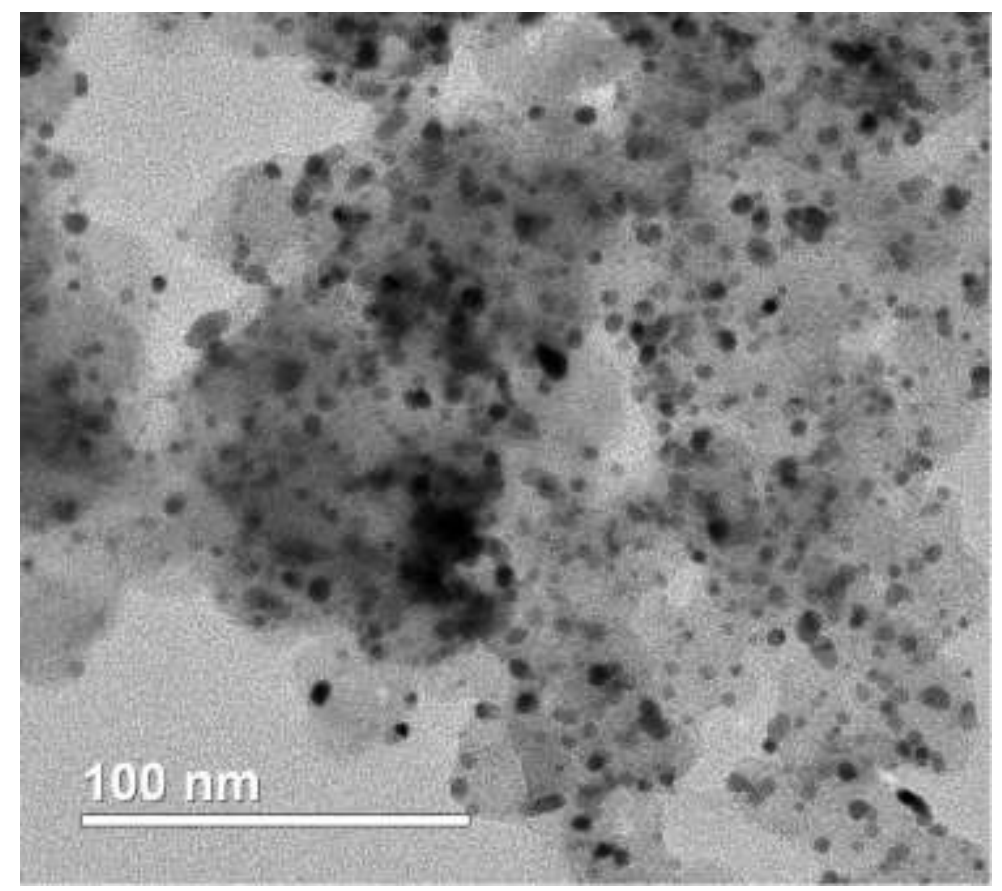

Figure S9. TEM images of the commercial Pt/C catalyst after 10000 cycles of ADT. 
Table S1. ECSAs, half-wave potentials, mass activities, and specific activities of Pd-Pt great icosahedra and commercial Pt/C before and after different cycles of ADT.

\begin{tabular}{llllll}
\hline Sample & Cycles & $\begin{array}{l}\text { ECSA } \\
\left(\mathrm{m}^{2} \mathrm{~g}^{-1} \mathrm{Pt}\right)\end{array}$ & $\begin{array}{l}\text { Half-wave } \\
\text { potential }(\mathrm{V})\end{array}$ & $\begin{array}{l}\text { Mass activity } \\
\left(\mathrm{A} \mathrm{mg}^{-1} \mathrm{Pt}\right)\end{array}$ & $\begin{array}{l}\text { Specific Activity } \\
\left(\mathrm{mA} \mathrm{cm}^{-2}\right)\end{array}$ \\
\hline Pd-Pt great & initial & 124.1 & 0.92 & 1.23 & 0.99 \\
icosahedra & 5000 & 107.3 & 0.91 & 1.18 & 1.10 \\
& 10000 & 106.8 & 0.91 & 1.09 & 1.02 \\
Commercial & initial & 71.2 & 0.87 & 0.15 & 0.22 \\
Pt/C & 5000 & 47.1 & 0.85 & 0.10 & 0.21 \\
& 10000 & 39.5 & 0.84 & 0.07 & 0.18 \\
\hline
\end{tabular}


Table S2. Comparative evaluation of electrocatalytic properties of the Pd-Pt great icosahedra with reported state-of-the-art Pd/Pt-based electrocatalysts.

\begin{tabular}{|c|c|c|c|c|}
\hline Sample & $\begin{array}{l}\text { ECSA } \\
\left(\mathrm{m}^{2} \mathrm{~g}^{-1} \mathrm{Pt}\right)\end{array}$ & $\begin{array}{l}\text { Mass activity } \\
\left(\mathrm{A} \mathrm{mg}^{-1}{ }_{\mathrm{Pt}}\right)\end{array}$ & $\begin{array}{l}\text { Specific activity } \\
\left(\mathrm{mA} \mathrm{cm}^{-2}\right)\end{array}$ & Ref. \\
\hline Pd-Pt great icosahedra & 124.1 & 1.23 & 0.99 & This work \\
\hline Pd@Pt core-shell concave decahedra & 95.9 & 1.60 & 1.66 & 3 \\
\hline Pd@Pt octahedra & 70 & 1.05 & 1.51 & 4 \\
\hline Pt-Pd concave nanocubes & 45.2 & 0.87 & 1.93 & 5 \\
\hline Pd@Pt core-shell concave nanocubes & 61 & 0.84 & 1.38 & 6 \\
\hline Pd@Pt core-shell nanowires & 202.5 & 0.81 & 0.4 & 7 \\
\hline Pd-Pt octahedral nanocages & 40.3 & 0.76 & 1.9 & 8 \\
\hline $\mathrm{Pd} @ \mathrm{Pt}_{1 \mathrm{~L}}$ octahedra & 74.3 & 0.75 & 1.01 & 9 \\
\hline Pd@Pt core-shell nanoparticles & 48.82 & 0.58 & 0.44 & 10 \\
\hline Pt-Pd popcorns & 47.4 & 0.57 & 0.52 & 11 \\
\hline PdPt bimetallic nanocrystals & 49.2 & 0.52 & 1.89 & 12 \\
\hline $\mathrm{Pd} @ \mathrm{Pt}_{2-3 \mathrm{~L}}$ octahedra & 53.6 & 0.49 & 0.91 & 13 \\
\hline Pt-Pd nanodendrites & 92.4 & 0.40 & 0.44 & 14 \\
\hline$\underline{\mathrm{Pd} @ \mathrm{Pt}_{4.5 \mathrm{~L}} \text { core-shell icosahedron }}$ & 46.0 & 0.39 & 0.83 & 15 \\
\hline Pt@Pd core-shell icosahedra & 38.8 & 0.29 & 0.74 & 16 \\
\hline Pd@Pt core-shell nanodots & 84.38 & 0.20 & 0.24 & 17 \\
\hline
\end{tabular}




\section{References}

(1) Yang, T. H.; Zhou, S.; Gilroy, K. D.; Figueroa-Cosme, L.; Lee, Y. H.; Wu, J. M.; Xia, Y., Autocatalytic Surface Reduction and Its Role in Controlling Seed-mediated Growth of Colloidal Metal Nanocrystals. Proc. Natl. Acad. Sci. U. S. A. 2017, 114, 13619-13624.

(2) Lee, C.-T.; Wang, H.; Zhao, M.; Yang, T.-H.; Vara, M.; Xia, Y., One-Pot Synthesis of Pd@PtnL Core-Shell Icosahedral Nanocrystals in High Throughput through a Quantitative Analysis of the Reduction Kinetics. Chem. Eur. J. 2019, 25, 5322-5329.

(3) Wang, X.; Vara, M.; Luo, M.; Huang, H.; Ruditskiy, A.; Park, J.; Bao, S.; Liu, J.; Howe, J.; Chi, M.; Xie, Z.; Xia, Y., Pd@Pt Core-Shell Concave Decahedra: A Class of Catalysts for the Oxygen Reduction Reaction with Enhanced Activity and Durability. J. Am. Chem. Soc. 2015, 137, 15036-15042.

(4) Zhou, M.; Wang, H.; Vara, M.; Hood, Z. D.; Luo, M.; Yang, T.-H.; Bao, S.; Chi, M.; Xiao, P.; Zhang, Y.; Xia, Y., Quantitative Analysis of the Reduction Kinetics Responsible for the One-Pot Synthesis of Pd-Pt Bimetallic Nanocrystals with Different Structures. J. Am. Chem. Soc. 2016, 138, 12263-12270.

(5) Wu, R.; Tsiakaras, P.; Shen, P. K., Facile Synthesis of Bimetallic Pt-Pd Symmetry-broken Concave Nanocubes and Their Enhanced Activity toward Oxygen Reduction Reaction. Appl. Catal. B Environ. 2019, 251, 49-56.

(6) Lee, S. R.; Park, J.; Gilroy, K. D.; Yang, X.; Figueroa-Cosme, L.; Ding, Y.; Xia, Y., Palladium@Platinum Concave Nanocubes with Enhanced Catalytic Activity toward Oxygen Reduction. ChemCatChem 2016, 8, 3082-3088.

(7) Li, H.-H.; Ma, S.-Y.; Fu, Q.-Q.; Liu, X.-J.; Wu, L.; Yu, S.-H., Scalable Bromide-Triggered Synthesis of Pd@Pt Core-Shell Ultrathin Nanowires with Enhanced Electrocatalytic Performance toward Oxygen Reduction Reaction. J. Am. Chem. Soc. 2015, 137, $7862-7868$.

(8) Hong, J. W.; Kang, S. W.; Choi, B.-S.; Kim, D.; Lee, S. B.; Han, S. W., Controlled Synthesis of Pd-Pt Alloy Hollow Nanostructures with Enhanced Catalytic Activities for Oxygen Reduction. ACS Nano 2012, 6, 2410-2419.

(9) Zhou, M.; Wang, H.; Elnabawy, A. O.; Hood, Z. D.; Chi, M.; Xiao, P.; Zhang, Y.; Mavrikakis, M.; Xia, Y., Facile One-Pot Synthesis of Pd@Pt $1 \mathrm{~L}$ Octahedra with Enhanced 
Activity and Durability toward Oxygen Reduction. Chem. Mater. 2019, 31, 1370-1380.

(10) Choi, R.; Choi, S.-I.; Choi, C. H.; Nam, K. M.; Woo, S. I.; Park, J. T.; Han, S. W., Designed Synthesis of Well-Defined Pd@Pt Core-Shell Nanoparticles with Controlled Shell Thickness as Efficient Oxygen Reduction Electrocatalysts. Chem. Eur. J. 2013, 19, 8190-8198.

(11) Ma, Y.; Yin, L.; Cao, G.; Huang, Q.; He, M.; Wei, W.; Zhao, H.; Zhang, D.; Wang, M.; Yang, T., Pt-Pd Bimetal Popcorn Nanocrystals: Enhancing the Catalytic Performance by Combination Effect of Stable Multipetals Nanostructure and Highly Accessible Active Sites. Small 2018, 14, 1703613.

(12) Cho, K. Y.; Yeom, Y. S.; Seo, H. Y.; Lee, A. S.; Huy Do, X.; Hong, J. P.; Jeong, H.-K.; Baek, K.-Y.; Yoon, H. G., Fine-sized Pt Nanoparticles Dispersed on PdPt Bimetallic Nanocrystals with Non-covalently Functionalized Graphene toward Synergistic Effects on the Oxygen Reduction Reaction. Electrochim. Acta 2017, 257, 412-422.

(13) Park, J.; Zhang, L.; Choi, S.-I.; Roling, L. T.; Lu, N.; Herron, J. A.; Xie, S.; Wang, J.; Kim, M. J.; Mavrikakis, M.; Xia, Y., Atomic Layer-by-Layer Deposition of Platinum on Palladium Octahedra for Enhanced Catalysts toward the Oxygen Reduction Reaction. ACS Nano 2015, 9, 2635-2647.

(14) Xiong, X.; Chen, W.; Wang, W.; Li, J.; Chen, S., Pt-Pd Nanodendrites as Oxygen Reduction Catalyst in Polymer-electrolyte-membrane Fuel Cell. Int. J. Hydrog. Energy 2017, 42, 25234-25243.

(15) Lee, C.-T.; Wang, H.; Zhao, M.; Yang, T.-H.; Vara, M.; Xia, Y., One-Pot Synthesis of Pd@PtnL Core-Shell Icosahedral Nanocrystals in High Throughput through a Quantitative Analysis of the Reduction Kinetics. Chem. Eur. J. 2019, 25, 5322-5329.

(16) He, D. S.; He, D.; Wang, J.; Lin, Y.; Yin, P.; Hong, X.; Wu, Y.; Li, Y., Ultrathin Icosahedral Pt-Enriched Nanocage with Excellent Oxygen Reduction Reaction Activity. J. Am. Chem. Soc. 2016, 138, 1494-1497.

(17) Li, S.; Liu, J.; Zhu, G.; Han, H., Pd@Pt Core-Shell Nanodots Arrays for Efficient Electrocatalytic Oxygen Reduction. ACS Appl. Nano Mater. 2019, 2, 3695-3700. 